\title{
Phytochemicals and uses of Moringa oleifera leaves in humans and animals in Sokoto
}

\author{
Sherifat Banke IDRIS* and Usman Rayyanu ADAMU
}

\author{
Department of Veterinary Pharmacology and Toxicology, Faculty of Veterinary Medicine, Usmanu Danfodiyo University, \\ Sokoto, Nigeria. \\ *Corresponding author. Email: bankidris67@gmail.com
}

Copyright (@) 2018 Idris and Adamu. This article remains permanently open access under the terms of the Creative Commons Attribution License 4.0, which permits unrestricted use, distribution, and reproduction in any medium, provided the original work is properly cited.

Received 23rd January, 2018; Accepted 14th February, 2018

\begin{abstract}
Moringa oleifera is a native plant of many countries in the world used for its medicinal, nutitional and economical benefits. In Nigeria, the leaves are sold either fresh or cooked as food and/or medicine. The phytochemicals present in Moringa oleifera leaves extracts belonging to the family Moringaceae was determined using serial extraction, with methanol, ethanol and water as solvent. The phytochemicals present were identified using standard chemicals and result interpretation, while the uses of this leaves in humans and animals were investigated with the use of questionnaire. The phytochemicals that were present in the leaves included: tannins, steroids, flavonoids, saponins, anthraquinones and alkaloids. Nine (9) medicinal uses of Moringa leaves were determined in animals and fifteen (15) medicinal uses of Moringa oleifera leaves in humans were established. The Presence of phytochemicals in the extracts suggests possible preventive and curative property of Moringa oleifera leaves in humans and animals.
\end{abstract}

Key words: Ethno veterinary medicine, medicinal plant, phytochemical analysis, questionnaire survey.

\section{INTRODUCTION}

Moringa oleifera, a multipurpose plant species belongs to the family Moringaceae (lqbal et al., 2006). Though it originated from India, it has been domesticated in Africa, Arabia, South East Asia, South America, Pacific and Caribbean Islands (Iqbal et al., 2006). Moringa oleifera has been naturalized in many tropic and sub-tropic regions worldwide, and is referred to by a number of names including: horseradish tree, drumstick tree, ben oil tree, miracle tree, Benzoline, Kelor, Marango, Mlonge, Mulangay, Saijihan, Sajna (Moyo et al., 2011). In Nigeria, Moringa is referred to as "Zogale" in Hausa, "Gawara" in Fulfulde, "Okwe oyibo" in Igbo, and "Ewe Igbale" in Yoruba (Adelanwa and Haruna, 2013). The leaves of Moringa plant can be eaten raw or cooked and this has served as source of vitamins and minerals due to its high nutritional value (Papillo, 2007). Moringa oleifera is consumed in most parts of the world as a means of personal health preservation and self-medication in various disease conditions because the leaves of this plant is characterized as contains vitamins, minerals, amino and fatty acids (Abdull et al., 2014). The leaves have also been reported to possess antibacterial, antifungal, antiviral, antidiabetic, antihypertensive and antioxidative properties (Agoyi et al., 2015; Kasolo et al., 2010). The use of traditional medicine in humans and animals for the treatment of infectious and non-infectious diseases is common in developing countries due to lack of access to quality orthodox health care, traditional beliefs, and poverty (Akinloye and Yinusa, 2011). Moringa oleifera leaves is believed to be an effective herb by natives of some developing countries and have been used traditionally in the treatment of different ailments and diseases. In this study, the phytochemicals present in Moringa oleifera leaves harvested from Sokoto state and the uses in humans and animals where investigated.

\section{MATERIALS AND METHODS}

\section{Identification and collection of plant material}

Fresh leaves of Moringa oleifera found around Sokoto State Central Market were collected. The plant's leaves were identified and authenticated at the botany unit of 
Department of Biological Sciences in Usmanu Danfodiyo University, Sokoto, Nigeria.

\section{Plant preparation}

The leaves were prepared according to the procedure described by Kudi et al. (1999). Briefly, the procedure involved drying the leaves in the laboratory to constant weight at room temperature. They were then grounded into powder using an electric blender. $5 \mathrm{~g}$ of the powder was mixed with $50 \mathrm{ml}$ ethanol ( $80 \%$ purity), $50 \mathrm{ml}$ methanol $(80 \%$ purity) and distilled water respectively. The preparations were left to stand for two days and then filtered using whatman ${ }^{\circledR}$ filter paper. The recovered filtrates were concentrated by evaporation in an oven which yielded a brown crude extract that was used for the study.

\section{Phytochemical analyses}

\section{Qualitative test}

This was done according to the methods of Okerulu and Aina (2001).

\section{Test for alkaloids}

About $1 \mathrm{ml}$ of $1 \%$ hydrochloric acid was added to $3 \mathrm{ml}$ of each extract in a test tube. The mixture was heated for 20 minutes and allowed to cool and filtered. 2 drops of Wagner's reagent were added to $1 \mathrm{ml}$ of each filtrate. A reddish brown precipitate indicates the presence of alkaloids.

\section{Test for tannins}

Exactly $1 \mathrm{ml}$ of freshly prepared $10 \%$ of potassium hydroxide was added to $1 \mathrm{ml}$ of each extract. A dirty white precipitate indicates presence of tannins.

\section{Test for flavonoids}

$1 \mathrm{ml}$ of $10 \%$ sodium hydroxide was added to $3 \mathrm{ml}$ of each extracts. Yellow colouration indicates the presence of flavonoids in the extract.

\section{Test for glycosides}

Exactly $10 \mathrm{ml}$ of $50 \%$ tetraoxosulphate (VI) acid was added to $1 \mathrm{ml}$ of each extract in a test tube. The mixture was heated in boiling water for 15 minutes. About $10 \mathrm{ml}$ of Fehling's solution was added and the mixture was boiled.
A brick-red precipitate was observed in the test mixture indicates the presence of glycosides.

\section{Test for steroids}

Presence of steroids was detected using Salkowski test in which 5 drops of concentrated tetraoxosulphate $(\mathrm{VI})$ acid were added to $1 \mathrm{ml}$ of each extract. Red colouration indicates presence of steroids in all the extracts.

\section{Test for anthraquinones}

This was carried out by adding $2 \mathrm{ml}$ of $25 \%$ Ammonia solution to $1 \mathrm{mg}$ of each extract and shaken. The presence of a bright red solution indicates the presence of anthraquinones.

\section{Test for saponins}

Presence of saponin was detected using frothing test. In this test, exactly $2 \mathrm{ml}$ of each extracts in a test tube was vigorously shaken for 2 minutes. Frothing observed in each extract indicate the presence of saponins.

\section{Test for coumarins}

Presence of coumarins was detected by adding $1 \mathrm{mg}$ of each extract to $2 \mathrm{ml}$ of water. The solution was then divided into 2 parts of $1 \mathrm{ml}$ each. To the first portion, $0.5 \mathrm{ml}$ of $10 \%$ ammonia solution was added while the second portion was used as a reference. The occurrence of an intense fluorescence under ultra violet light indicated the presence of coumarins and its derivatives.

\section{Questionnaire survey}

This was done according to the method of Kasolo et al. (2010). Over a period of three weeks, a cross sectional study with the quantitative and qualitative method of data collection used in survey was carried out among house hold members aged between 20 years to 82 years in Sokoto metropolis. They were interviewed in their homes in the local language (Hausa) which was translated back to English on the uses of Moringa oleifera leaves both fresh and dried form in humans and animals.

\section{Data collection for uses of Moringa oleifera in humans and animals}

A total of one hundred questionnaires were used to collect data from the respondents on the use on $M$. oleifera in both 
Table 1. Phytochemical Constituents of Moringa oleifera leaves.

\begin{tabular}{lccc}
\hline Test & Methanol extract & Ethanol extract & Distilled water extract \\
\hline Saponins & +++ & +++ & +++ \\
Coumarins & ---- & --- & ---- \\
Tannins & +++ & ++ & + \\
Alkaloids & +++ & +++ & ++ \\
Flavonoids & +++ & +++ & +++ \\
Glycosides & +++ & +++ & +++ \\
Steroids & +++ & +++ & +++ \\
Anthraquinones & ++ & ++ & + \\
\hline
\end{tabular}

- = absent/undetectable, $+=$ Present in trace amount (slight colour change), ++ = Present in moderate amount (Moderate colour change), $+++=$ Present in large amount (intense change in colour).

humans and animals. Data was also collected on respondent's social-(demographic) characteristic (age, sex, educational level, occupation, closeness to health centre). It also included knowledge and the use of $M$. oleifera in their homes and community in humans and animals.

\section{RESULTS AND DISCUSSION}

Results of phytochemical constituents of Moringa oleifera leaves, reported uses of $M$. oleifera in humans and animals in Sokoto state are presented in Tables 1,2 and 3.

Phytochemical screening of Moringa oleifera (Table 1) showed that saponins, tannins, alkaloids, flavonoids, anthraquinones, glycosides and steroids were present in the leaves. These phytochemicals were present in all 3 extracts. For tannins, the methanol extract had a deep dirty white colour, however, the ethanol and distilled water extracts had less deep white colour respectively. Alkaloids were detected in both methanol and ethanol extracts however, only a faint reddish brown colour was seen in the distilled water extract compared to the other solvents. Saponins, flavonoids, steroids and glycosides were detected in all the solvents with intense colour change. Anthraquinones were present all the three extracts with decreasing colour intensity in the distilled water extract. Coumarins were absent in all the solvents.

Other researchers have reported the presence of these phytochemicals in M. oleifera (Kasolo et al., 2010; Devbhuti et al., 2009). Most plants have an intrinsic limitless ability to synthesize various primary and secondary metabolites. The presence of which can be used as to explain the biological effects like antiparasitic, antidiarrhoea, antibacterial, antioxidant and so on. Flavonoids which was present in all three extracts in these study are polyphenolic compounds present in a wide variety of plants, they possess anti-inflammatory, antioxidative properties (Al-Numair et al., 2015a), antidiabetic ((Luo et al., 2015; Al-Numair et al., 2015b) and antihypertensive properties (Ayinde et al., 2007).

Anthraquinones present in $M$. oleifera has laxative
Table 2. Reported uses of M. Oleifera in humans in Sokoto State.

\begin{tabular}{lc}
\hline Use & $\mathbf{N}(\%)$ \\
\hline Antibacterial & $21(21)$ \\
Antihypertensive & $59(59)$ \\
Antihelminthic & $12(12)$ \\
Ulcer & $45(45)$ \\
Blood tonic & $14(14)$ \\
Diuretics & $2(2)$ \\
Athrithis & $1(1)$ \\
Digestion Aid & $11(11)$ \\
Yellow Fever & $1(1)$ \\
Malaria & $2(2)$ \\
Antiallergy & $1(1)$ \\
Typhoid & $1(1)$ \\
Vitamin source & $1(1)$ \\
Anti allergy & $31(31)$ \\
Mgt of scorpion stings & $1(1)$ \\
\hline
\end{tabular}

$\mathrm{N}=$ No. of respondents.

effects and may be responsible for its use in the treatment of digestive problems as mentioned by some respondents. Tannins are a group of polymeric phenolic metabolite which possess antimicrobial, anticarcinogenic and antimutagenic properties (Ryszard, 2007). Steroids also present in the leaves of this plant have been documented to have anti-carcinogenic effects (Subramanion et al., 2011). Saponins are triterpene glycosides that play an important role in chemical defence and possess a wide array of pharmacological effects (Caulier et al, 2011). Glycosides present in $M$. oleifera leaves have been documented to have antihypertensive effects (Faizi et al., 1995). Alkaloids are known to have analgesic and antiinflammatory effects (Cordell, 1983). The presence of these metabolites in $M$. oleifera leaves may be responsible for some of the effects reported by the respondents following the consumption of these leaves by humans and animals. The questionnaire analysis, revealed that most of the participant were aged between 30 to 50 years (80:80\%), 
Table 3. Use of M.oleifera in animals.

\begin{tabular}{lc}
\hline Use & $\mathbf{N}(\%)$ \\
\hline Antibacterial & $3(3)$ \\
Antidiarrhoea & $4(4)$ \\
Ruminal stasis & $3(3)$ \\
Fatenning & $2(2)$ \\
Weakness & $3(3)$ \\
Milk production & $3(3)$ \\
Growth promoter & $3(3)$ \\
Feed supplement & $24(24)$ \\
Paste on wounds & $6(6)$ \\
\hline
\end{tabular}

$\mathrm{N}=$ No. of respondents.

there were more males $(78: 78 \%)$ than females $(22: 22 \%)$ the participants were from different occupation $(21 \%$ were business men/women, $17 \%$ were civil servants, $18 \%$ were farmers, $17 \%$ were house wives, $16 \%$ were students, $5 \%$ carpenters, $4 \%$ gardeners and $2 \%$ were retired from their jobs with $31 \%$ having attended only Quranic (Islamiyah) school, $35 \%$ with only secondary certificate, $18 \%$ with primary education, $10 \%$ with first degree and $2 \%$ with MSc. Most of the respondents (91:91\%) lived less than $3 \mathrm{~km}$ from the nearest health centres. All the respondents had the knowledge of the use of Moringa oleifera in humans $(100 \%)$ and it was found that there were fifteen uses of the plant in Sokoto state (Table 2).

Other works revealed 45 (Fahey, 2005) uses around the globe and 24 (kasolo et al., 2010) uses of M. oleifera leaves in Uganda. The difference in number of ailments it is used to treat may be due to proximity to health centres since most of the respondents live a distance less than 3 $\mathrm{km}$ to a health centre, and may have accepted the orthodox method of treatment rather than resort to taking traditional medicine. Furthermore, this may be due to duplication of names in other languages and merging more than one disease into one in the local language (Kasolo et al., 2010). Majority (81:81\%) of the respondents kept household domestic animals in both intensive (14:14\%), semi intensive (58:58\%) and extensive (9:9\%) system of management out of which (56:56\%) had no knowledge of the use of the plant in animals while $(25: 25 \%)$ used the plant in animals, of which nine uses of $M$. oleifera leaves in animals were identified (Table 3 ).

This number may be due to the competition with humans for the leaves of $M$. oleifera, which many farmers find expensive to incorporate into animal feed and the lack of knowledge that this leaves can be used in animals. This study has established the fact that $M$. oleifera leaves in Sokoto are used for treatment of nine conditions in animals.

\section{Conclusion}

It was concluded that $M$. oleifera leaves has 15 uses in humans and 9 uses in animals in Sokoto state, Nigeria and the phytochemicals present in it is indicative of curative and preventive properties of this leaves.

\section{CONFLICT OF INTEREST}

The authors declare that they have no conflict of interest.

\section{REFERENCES}

Abdull, R., Ahmad, F., Ibrahim, M. D., \& Kntayya, S. B. (2014). Health benefits of Moringa oleifera. Asian Pacific Journal of Cancer Prevention, 15(20), 8571-8576.

Adelanwa, M. A., \& Haruna, H. B. (2013). Survey of some plants found in Guraralocal government area of Niger State, Nigeria. International Journal of Applied Biological Science Research, 5(1), 43-54.

Agoyi, E. E., Elie, A. P., Amoussa, W., Achilla, E. A., Romain, G. K., \& Brice, S. (2015). Morphological Verification, cultivation techniques and Management Practices o23f Moringa Oleifera in Southern Benin (West African). International Journal of Agronomy and Agricultural Research, 6(3), 97-105.

Akinloye, O., \& Yinusa, R. (2011). Assessment of complementary and alternative medicine(CAM) usage to enhance male sexual performance in Ogbomoso metropolis. Journal of Public Health and Epidemiology, 3, 271-274.

Al-Numair, K. S., Chandramohan, G., Veeramani, C., \& Alsaif, M. A. (2015a). Ameliorative effect of kaempferol, a flavonoid, on oxidative stress in streptozotocin-induced diabetic rats. Redox Report, 20(5), 198-209.

Al-Numair, K. S., Veeramani, C., Alsaif, M. A., \& Chandramohan, G. (2015b). Influence of kaempferol, a flavonoid compound, on membrane-bound ATPases in streptozotocin-induced diabetic rats. Pharmaceutical Biology, 53(9), 1372-1378.

Ayinde, B. A., Onwukaeme, D. N., \& Omogbai, E. K. I. (2007). Isolation and characterization of two phenolic compounds from the stem bark of Musanga cecropioides R. Brown (Moraceae). Acta Phenolic Pharmacology, 64,183-185.

Caulier, G., Van Dyck, S., Gerbaux, P., Eeckhaut, I., \& Flammang, P. (2011). Review of saponin diversity in sea cucumbers belonging to the family Holothuriidae. SPC Bechede-mer Inf. Bull, 31(1), 48-54.

Cordell, G. A. (1983). Introduction to Alkaloids: pharmacology and biology, in: Alkaloids Chemical and Biological Perspectives. Volume 3. Wiley, New York, Pp. 1-274.

Devbhuti, D., Gupta, J. K., Devbhuti, P., \& Bose, A. (2009). Phytochemical and acute toxicity study on Tinospora tomentosa Miers. Acta. Phytochemical Pharmarcology, 66, 8992.

Fahey, J. W. (2005). Moringa oleifera. A review of the medical evidence for its nutritional, therapeutic, \& prophylactic properties part I. Trees for life Journal, 1(5)

Faizi, S., Siddiqui., B. S., Siddiqui, R. Aftab, K., \& Gilani. A. (1995). Fully acetylated carbamate and hypotensive thiocarbamate glycosides from Moringa oleifera. Phytochemistry, 38, 957-953.

lqbal, S., \& Bhanger, M. I. (2006). Effect of Season and Production Location on antioxidant activity of Moringa oleifera leaves grown in Pakistan. Journal of Food Composition and analysis, 19, 544-551.

Kasolo, J. N., Gabriel, S. B., Lonzy, O., Josheph, O., \& Jasper, W. O. (2010). Phytochemicals and uses of Moringa Oleifera leaves in Ugandan Rural Communities. Journal of Medical Plants research, 4(9), 753-757. 
Kudi, A. C., Umoh, J. U., Eduvic, L. O., \& Gefu, J. (1999). Screening of some Nigerian Medical Plants for Antibacterial activity. Journal Ethnopharmacology, 67, 225-228.

Luo, C., Yang, H., \& Tang C. (2015). Kaempferol alleviates insulin resistance via hepatic IKK/NF- $\kappa \mathrm{B}$ signal in type 2 diabetic rats. International Immunopharmacology, 28,744-750.

Moyo, B., Masika, P. J., Hugo, A., \& Muchenje, V. (2011). Nutritional characterization of Moringa (Moringa oleifera Lam.) leaves. African Journal of Biotechnology, 10(60), 1292512933.

Okerulu, I. O., \& Aina, J. C. (2001). The Phytochemical analysis and antibacterial screening of extracts of Tetracarpium conophorum. Journal of Chemistry Society of Nigeria, 26(1), 53-55.
Papillo, J., (2007). Moringa oleifera: the multi-purpose wonder tree. 〈http://peacecorps. mtu.edu/resources/studentprojects/ moringa.htm> Michigan Technological University, Michigan, USA.

Ryszard, A. (2007). Tannins: the new natural antioxidants. European Journal of lipid science technology, 109, 549-551.

Subramanion, L. J., Zakaria, Z., \& Srinivasan, S. (2011). Phytochemical screening, DPPH free radical scavenging and xanthine oxidase inhibitory activities of Cassia fistula seeds extract. Journal of Medicinal Plant Research, 5(10),1941-1947. 